\title{
Measuring Feed Force in Machining using A Strain Gage
}

\author{
Salman A. F. Siregara, Agus Triono ${ }^{b}$, Mahros Darsinc, Santoso Mulyadid \\ $a, b, c, d$ Department of Mechanical Engineering, the University of Jember \\ Jl. Kalimantan 37 Jember Jawa Timur 68121 Indonesia. \\ Telp : +62 331-330224, Fax : +62 331-410243 \\ e-mail: mahros.teknik@unej.ac.id
}

\begin{abstract}
Measuring the forces that work during machining has been being concerned by researchers for years. There are three main forces that work in turning: thrust force, axial force, and radial force. Thus, feeding force measurement is needed in machine manufacturing. This research attempts to develop measurement method through feeding force, using strain gauge sensor. The aim of measurement of feeding force in this research is to find out the influence parameter of machine towards feeding force. The research used experimental method with design experiment Taguchi to know the influence of machine parameters to feeding force in turning process. The measurement tool is strain gauge sensor connected to cutting tool. The workspace is alluminium 6061 with $15 \mathrm{~mm}$ in diameter and $150 \mathrm{~mm}$ in length. The parameters for this research are speed rate $(140 \mathrm{rpm}, 215 \mathrm{rpm}$, and $330 \mathrm{rpm})$, feed rate $(0,043 \mathrm{~mm} / \mathrm{r}, 0,065$ $\mathrm{mm} / \mathrm{r}$, and $0,081 \mathrm{~mm} / \mathrm{r})$, and depth of cut $(0,2 \mathrm{~mm}, 0,4 \mathrm{~mm}$, and $0,6 \mathrm{~mm})$. The result showed that speed rate is the most significant parameter, with the contribution percentage is $92 \%$. Speed rate and feed rate parameter have insignificant influence. The contribution percentage of speed rate is $2 \%$ while the feed rate has \% contribution percentage. The conclusion of the research is that the bigger number of speed rate, the bigger feeding force it will have.
\end{abstract}

Keywords: feeding force; strain gauge; ANOVA;

\section{INTRODUCTION}

In machining, there are some forces work during chips relieving, i.e. cutting force, thrust force, friction force and normal force. Cutting force $(\mathrm{Fc})$ acts in the direction of cutting speed $(\mathrm{V})$ and supplies energy required for cutting. Thrust force $(\mathrm{Ft})$ acts in a direction normal to cutting velocity, perpendicular to workpiece (Fig.1b). The resultant force, R can be resolved into two components: friction force (Fs) along the tool-chip interface and normal force $(N)$ that perpendicular to it. Friction force $(F)$ and normal force to friction $N$. Shear force (Fs) and normal force to shear Fn (Fig. 1a). Forces F, N, Fs, and Fn cannot be directly measured. Forces acting on the tool that can be measured: cutting force $(\mathrm{Fc})$ and thrust force (Ft) [1]. In other literatures cutting force was called as feed(ing) force due to this force mainly affected of, such as [2]. In this manuscript the term of feed force is used with the same meaning as cutting force.

The turning process requires feeding force in material feeding. Feeding force is influenced mainly by the feeding [2]. However, several parameters also affected it, including cutting speed, depth of feed, depth of cut, the geometry of tool, type of workpiece material, and how to cooling down the tool-workpiece interface [3]. Feeding force affects surface roughness, energy consumption, tool life, etc. Therefore, measurement of the feeding force in the machining process is essential. Laakso et al. [4] conducts research on feed force using parameters such as the edge geometry of the tool affects the plowing force. They considered that Coulomb friction also affects the change in feed force [4]. Thangarasu et al. conducted research on depth of cut, spindle speed, and feed rate on cutting forces. The 
results obtained from this study was that the spindle speed was out weight by $92.226 \%$ to cutting force [5]. Manjunatha and Umesh (2014) also conduced research on depth of cut, spindle speed, and feed rate to get the maximum value from feed force. The results obtained that the depth of cut contributed up to $78.3 \%$ toward the feed force [6]. In 2016, there was a conducted research on the design and development of semiconductor strain force sensors by Zhao et al. [7]. This research conducted development of direct measurement methods feed force using strains gauge. Selection of strain gauge sensors to measure cutting style because it has a higher accuracy and measurement results that can be directly seen and stored on PC / display. Measurements made in the turning process where the sensor will be put on the tool post to get a response feeding force concerning machining parameters [7].
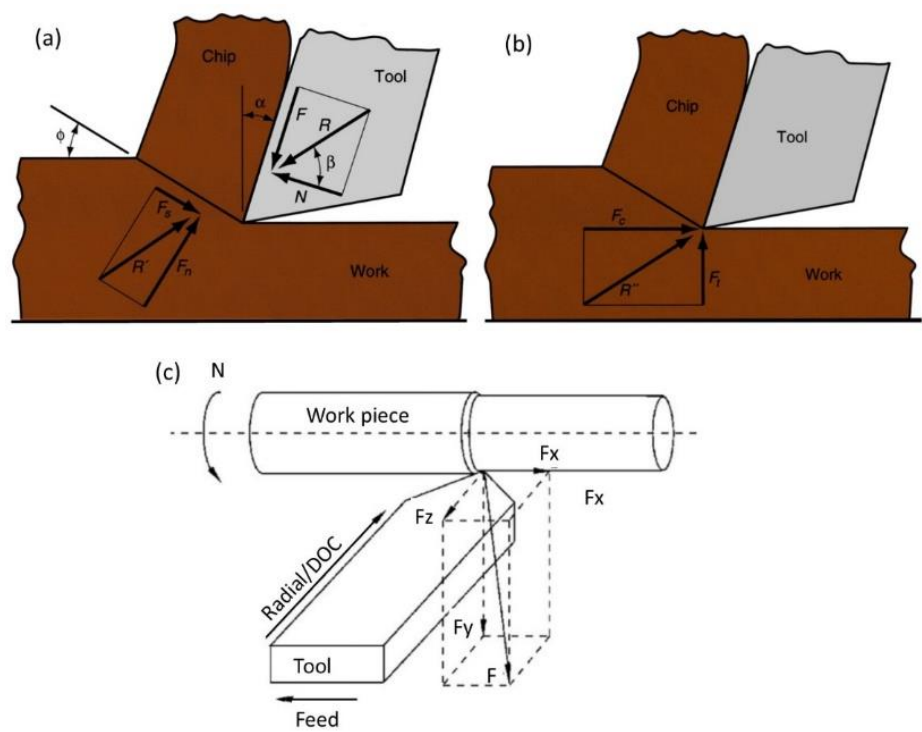

Figure 1. Forces that works in machining, (a) can not be measured forces, (b) can be measured forces, (c) other name of can be measured forces

\section{Methods}

The measuring force used in this study is the strain gauge sensor connected to the tool. Detail of tool, devices and procedures of feed measurements would be described in the following section. Further observations toward measured feed force by modifying some machining parameters. To simplify the experiments and variation, yet keep the accuracy and confidential of results, the Taguchi experimental design was employed in this research.

\subsection{Tools and Materials}

\subsubsection{Tools}
a) $66236 \times 1000$ GUT Lathe Machine
b) Load Cell
c) Strain gauge sensor Type 10-120-C1-11 L1M 2 R
d) Amplifier
e) Data logger (ADAM 4018)
f) Laptop / Display

\subsubsection{Materials}

a) HSS (High Speed Steel) chisel size $3 / 4$ "

b) Aluminum $6061 \varnothing 15 \mathrm{~mm} \times 150 \mathrm{~mm}$

\subsection{Research Procedures}

The working principle of the feeding force testing tool is that the load cell is clamped on the tool post and the tool is clamped to the load cell. The cutting process begins when the tool touches the workpiece and the strain gauge sensor will read then forward it to the 
Wheatstone bridge to stabilize the incoming voltage. The output voltage from the Wheatstone bridge is passed on to the amplifier which then enters the data logger. The data logger then proceeds to the display or PC. The test equipment scheme is shown in Figure 2.

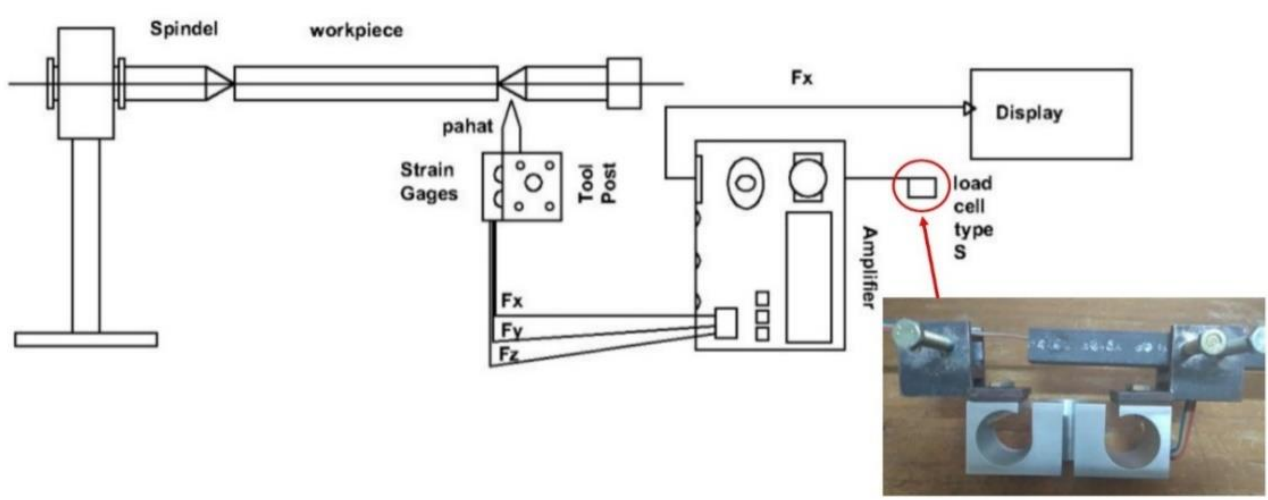

Figure 3. The schematic diagram for the feed force sensing and recording.

This study used 3 control factors with 3 levels for each factor. The control factors and levels used in this study is shown in Table 1.

Table 1. Control factors and research factor levels

\begin{tabular}{llccc}
\hline \multirow{2}{*}{ Symbol } & Control Factor & \multicolumn{3}{c}{ Factor Level } \\
\cline { 3 - 5 } & & $\mathbf{1}$ & $\mathbf{2}$ & $\mathbf{3}$ \\
\hline $\mathrm{N}$ & Spindle speed $(\mathrm{rpm})$ & 140 & 215 & 330 \\
$\mathrm{~F}$ & Feeding $(\mathrm{mm} / \mathrm{r})$ & 0.043 & 0.065 & 0.081 \\
$\mathrm{D}$ & Depth of cut $(\mathrm{mm})$ & 0.2 & 0.4 & 0.6 \\
\hline
\end{tabular}

\section{Result AND Discussion}

\subsection{Verification Process}

The verification process is used to determine the increase in voltage to the load. The results of the calibration are then changed in the form of a formula to convert from the electric voltage $(\mathrm{mV})$ to mass units (grams). The calibration process uses vise to clamp the load cell so that the position can be adjusted in the direction of the feeding force. The loading process is carried out at the end of the load cell using a scale lead with a load increasing from 49.8 - 597.3 grams. Retrieval of this data takes 12 data with 3 repetitions. The plot of the verification graph, namely the linearity verification of mass with voltage, is shown in Figure 4.

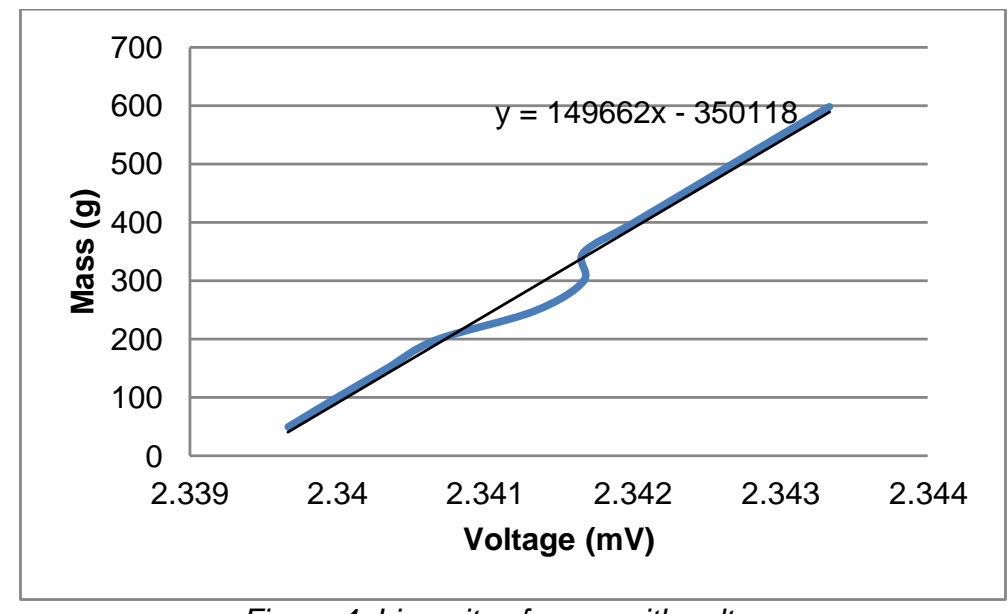

Figure 4. Linearity of mass with voltage 
The linear equation is used to convert millivolt $(\mathrm{mV})$ output data into grams $(\mathrm{g})$ mass units, after which it is converted into Newton units $(\mathrm{N})$ multiplied by the acceleration of gravity. The process of data conversion is done by changing the $x$ variable in the formula into the output voltage during the turning process.

This results is adequate for a traditional system with a low cost sensor in compare to the more advantage system of force measurement using delicate sensor Luo (2018) [8] and artificial intelligent such as result of $\mathrm{Li}(2000)$ [9]. The result is also comparable to that of using dynamometer Wan (2016) [10] is term of sensitivity to the input signal.

\subsection{Response Data Results}

The results of the response data are the results of data in the turning process of the 6061 aluminum workpiece with the HSS tool. For the design of experimental data retrieval using orthogonal arrays tables of the Taguchi L9 method $\left(3^{4}\right)$ with 3 times replication. When the data turning process is strived to have accurate sensitivity by adjusting the gain and offset of the amplifier. Each data collection from measurements that come out as many as hundreds of data. It is sufficiently represented by the mean data in each stable condition on the plot of the response graph for statistical calculations. The force response data graph is shown in Figure 5.

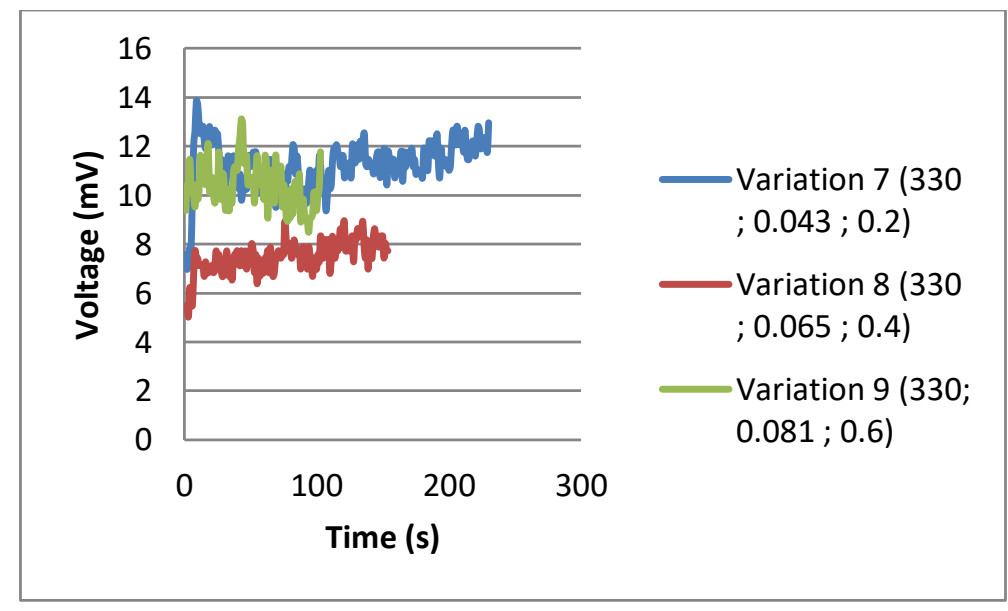

Figure 5. Graph of force response variations 7, 8 and 9

According to Figure 4, the response data for each variation experienced ups and downs. The graphs fluctuations were caused by a shift in the offset value of the strain gauge. The offset value can shift up to $\pm 0.07 \mathrm{mV}$. In the turning process, there is a vibration in the tool to allow a shift in the movement of the tool when cutting the workpiece.

\subsection{Analysis of Variance (ANOVA)}

\subsubsection{Response from Average Results}

Feeding force testing is done based on the L9 orthogonal matrix with each variation replicated three times. The average data of each variation that has been obtained in the test is used to find the percent value of the contribution which then can be used to determine the effect of the parameters on the target response to be achieved. In this study, the mean data for feeding force $(\mathrm{Ff})$ is shown in Table 2.

The overall average feeding force data from 3 repetitions would be used to calculate the average response value of the speed rate, feed rate, and depth of cut parameters. The following Table 3 is the result of calculating the average response value of each level of the machining parameter. 


\begin{tabular}{ccccr} 
No & N (RPM) & $\begin{array}{c}\text { Feed Rate } \\
\text { (mm/rot) }\end{array}$ & $\begin{array}{c}\text { Depth of Cut } \\
\text { (mm) }\end{array}$ & Average \\
\hline 1 & 140 & 0.043 & 0.2 & 112.143 \\
2 & 140 & 0.065 & 0.4 & 54.004 \\
3 & 140 & 0.081 & 0.6 & 94.780 \\
4 & 215 & 0.043 & 0.4 & 273.180 \\
5 & 215 & 0.065 & 0.6 & 263.458 \\
6 & 215 & 0.081 & 0.2 & 333.237 \\
7 & 330 & 0.043 & 0.6 & 131.726 \\
8 & 330 & 0.065 & 0.2 & 72.101 \\
9 & 420 & 0.081 & 0.4 & 107.588 \\
\hline
\end{tabular}

Table 3. Average response values for each level

\begin{tabular}{lccc}
\hline \multicolumn{1}{c}{$\begin{array}{c}\text { Machining } \\
\text { Parameters }\end{array}$} & \multicolumn{3}{c}{ Level } \\
\cline { 2 - 4 } & $\mathbf{1}$ & $\mathbf{2}$ & $\mathbf{3}$ \\
\hline $\mathrm{n}(\mathrm{rpm})$ & 86.975 & 289.958 & 102.018 \\
$\mathrm{f}(\mathrm{mm} / \mathrm{r})$ & 172.349 & 129.854 & 129.854 \\
$\mathrm{~d}(\mathrm{~mm})$ & 172.494 & 143.137 & 163.322 \\
Average & 154.440 & & \\
\hline
\end{tabular}

The followings are ANOVA results with $\mathrm{S} / \mathrm{N}$ ratio along with the $\mathrm{F}$ value with a significant level of $5 \% \alpha=0.05$ with a value of $F(0.05 ; 2 ; 2)=19.00$, overall is shown in Table 4.

Table 4. ANOVA results with an average $S / N$ ratio for the cutting force

\begin{tabular}{lcrrrr}
\hline \multicolumn{1}{c}{ Parameter } & DF & \multicolumn{1}{c}{ SS } & \multicolumn{1}{c}{ MS } & \multicolumn{1}{c}{ F } & P \\
\hline $\mathrm{N}$ & 2 & 76994.176 & 38497.088 & 335.995 & $92 \%$ \\
$\mathrm{~F}$ & 2 & 4589.023 & 2294.511 & 20.026 & $2 \%$ \\
$\mathrm{D}$ & 2 & 1597.725 & 798.862 & 6.972 & $2 \%$ \\
Residual error & 2 & 229.152 & 114.576 & & $4 \%$ \\
Total & 8 & & & & \\
\hline
\end{tabular}

The percentage contribution shows the portion of the parameter to the total variation of responses observed. In this Table 4 , the error is only $4 \%$, therefore the results is acceptable for further analysis [11], [12]. This research evident that spindle rotation contributes 92\% toward the feed force. In contrast, Manjunatha and Umesh (2014) obtained that the feed force mainly affected by the depth of cut by $78.3 \%$ [6]. Another research shown cutting force was influenced in order by feed rate, depth of cut and cutting, as described by Sivaraman et al. [13]. The difference result may because the different material and being machined and the tools used and other condition which is assumed as the constant in fact these variables influence the forces.

The most possible cause of difference is the low sensitivity of the load cell. Another possible cause is the zero point shifting (gain and offset) in the data acquisition system arrangement which result in alteration of range result of measurement. It keeps fluctuate up and down. Sensitivity is a measurement specification which measure the smallest absolute amount of change that can be detected by a measurement [14]. It can be identified by changing of gradient to the time. The shorter the range of the alteration the better is the sensitivity of the measuring device. In this experiments, sensitivity and zero (datum) was manually controlled by gain and offset. Calibration shows that increased range was 0.0006 $\mathrm{mV}$ and dropping of $-12.34 \mathrm{mV}$. 


\section{CONCLUSION}

Based on the results of experiments measuring feed force in the turning process, the

following conclusions can be drawn:

1) Measurement with a strain gauge sensor produces an average output data with a maximum sensitivity of $0,0007 \mathrm{mV}$ by producing a linearity equation from the calibration process that is $y=149662 x-350118$.

2) The most optimal feeding force response is at spindle speed 140 , feed rate 0.065 , and depth of cut 0.4 .

3) The speed rate parameter has a significant effect from other parameters by contributing $92 \%$ using ANOVA. Besides, the feed rate and depth of cut parameters are the second parameters with a contribution of $2 \%$ each.

This research discusses how the influence of the speed rate, feed rate and depth of cut parameters on the force of feeding direction on the axial axis. However, in the process of measurement, there was a technical error which caused an inaccurate data collection process. Suggestions for further research are expected to ensure the sensitivity of the measuring instrument sensor and set a zero point (offset) so that the shifting of data can be minimized.

\section{REFERENCES}

1. S. Kalpakjian and S. Schmid, "Manufacturing Engineering and Technology", 4th ed. Pearson, 2001.

2. S. E. Oraby and D. R. Hayhurst, "Tool life determination based on the measurement of wear and tool force ratio variation," Int. J. Mach. Tools Manuf., vol. 44, no. 12-13, pp. 1261-1269, 2004. DOI: https://doi.org/10.1016/i.ijmachtools.2004.04.018

3. R. Dubovska, J. Majerik, and I. Baska, "Experimental Measurement of Cutting Forces in the Turning Technology," Daaam Int. Sci. B. 2012, pp. 255-266, 2012.

4. S. V. A. Laakso, M. Agmell, and J. E. Ståhl, "The mystery of missing feed force - The effect of friction models, flank wear and ploughing on feed force in metal cutting simulations," J. Manuf. Process., vol. 33, no. April, pp. 268-277, 2018. DOI: https://doi.org/10.1016/i.jmapro.2018.05.024

5. S. K. Thangarasu, S. Shankar, A. Tony Thomas, and G. Sridhar, "Prediction of Cutting Force in Turning Process-an Experimental Approach," IOP Conf. Ser. Mater. Sci. Eng., vol. 310 , no. 1,2018

6. R. Manjunatha and C. K. Umesh, "Optimization of Tangential Force, Feed Force and Surface Roughness Using Taguchi Technique in Turning Operation," Procedia Mater. Sci., vol. 5, pp. 1685-1691, 2014. DOI: https://doi.org/10.1016/j.mspro.2014.07.357

7. Y. Zhao et al., "Design and development of a cutting force sensor based on semiconductive strain gauge," Sensors Actuators, A Phys., vol. 237, pp. 119-127, 2016. DOI: https://doi.org/10.1016/..sna.2015.11.017

8. M. Luo, Z. Chong, and D. Liu, "Cutting Forces Measurement for Milling Process by Using Working Tables with Integrated PVDF," Sensors, vol. 18, no. 4031, pp. 1-13, 2018. DOI: https://doi.org/10.3390/s18114031

9. X. Li, P. K. Venuvinod, and M. K. Chen, "Feed Cutting Force Estimation from the Current Measurement with Hybrid Learning," Int J Adv Manuf Technol, vol. 16, pp. 859862, 2000. DOI: https://doi.org/10.1007/s001700070002

10. M. Wan, W. Yin, and W. Zhang, "Study on the correction of cutting force measurement with table dynamometer," Procedia CIRP, vol. 56, pp. 119-123, 2016. DOI: https://doi.org/10.1016/i.procir.2016.10.035

11. M. Darsin, T. Pasang, and Z. Chen, "Forces Perspective of Drillability of Titanium Alloy 6Al-2Sn-4Zr-6Mo," J. Energy, Mech. Mater. Manuf. Eng., vol. 3, no. 1, p. 23, Jun. 2018. DOI: https://doi.org/10.22219/jemmme.v3i1.5825

12. N. Khanna and J. P. Davim, "Design-of-experiments application in machining titanium alloys for aerospace structural components," vol. 61, pp. 280-290, 2015. DOI: https://doi.org/10.1016/i.measurement.2014.10.059

13. V. Sivaraman, S. Sankaran, and L. Vijayaraghavan, "The Effect of Cutting Parameters on Cutting Force During Turning Multiphase Microalloyed Steel," vol. 4, pp. 157-160, 2012. DOI: https://doi.org/10.1016/i.procir.2012.10.028

14. Q. Liu and T. Homma, "A New Importance Measure for Sensitivity Analysis," J. Nucl. Sci. Technol. ISSN, vol. 3131, no. 2010, pp. 53-61, 2012. DOI: $10.1080 / 18811248.2010 .9711927$ 